Educational Research for Social Change (ERSC)

Volume: 6 No. 2, September 2017

pp. $60-75$

ersc.nmmu.ac.za

ISSN: 2221-4070

\title{
A Multidisciplinary Approach to University Engagement: Key Considerations for Dynamic Mental Health Teaching and Service Provision to a Disadvantaged Community
}

Rosemary Exner

Nelson Mandela University

rosemary.exner@nmmu.ac.za

Jennifer Jansen

Nelson Mandela University

jennifer.jansen@nmmu.ac.za

Louise Stroud

Nelson Mandela University

louise.stroud@nmmu.ac.za

Mingon du Preez

Nelson Mandela University

mingondp@gmail.com

\section{Abstract}

Scholarship has an obligation to society in that what is discovered through research and what is taught in the lecture hall should extend beyond the classroom and benefit the community. As a hub of training and knowledge in a local community, the challenge for a university exists in integrating community needs and university resources. Mental health is one discipline where this is particularly relevant and urgent due to the growing need for mental health interventions, particularly in under-serviced communities. A university is well positioned to develop a dynamic multidisciplinary approach to the biopsychosocial teaching of mental health practice and community service provision because it has extensive access to networks of current and future professionals. This reflective article explains the development of such a university-community collaborative initiative attached to the Missionvale Psychology Centre (MPC) at the Nelson Mandela University (NMU) located in Port Elizabeth. It examines the broader teaching and learning opportunities afforded the students as well as the need to deliver a much needed service to the local community. In this article, the initiative is qualitatively analysed through the lens of a combination of observational experience and self-reflection. Insights gained and lessons learnt could benefit other health professionals in comparable positions who are faced with similar challenges in response to student training agendas and the social responsibility of universities in developing countries. 
Keywords: community engagement, mental health, biopsychosocial, multidisciplinary, tranformative learning

Copyright: @ 2017 Exner, Jansen, Stroud \& Du Preez

This is an open access article distributed under the terms of the Creative Common Attribution NonCommercial License, which permits unrestricted non-commercial use, distribution, and reproduction in any medium, provided the original author and source are credited.

\section{Please reference as:}

Exner, R., Jansen, J., Stroud, L. \& Du Preez, M. (2017). A Multidisciplinary Approach to University Engagement: Key Considerations for Dynamic Mental Health Teaching and Service Provision to a Disadvantaged Community. Educational Research for Social Change, 5(2), 60-75. http://dx.doi.org/10.17159/2221-4070/2017/v6i2a5

\section{Introduction and Background}

Meeting community needs within an underserviced socioeconomic context requires a dynamic approach because the landscape is continuously changing-people are perpetually moving between urban areas, townships, and rural areas to find housing, work, and access to social and economic infrastructure in what they may perceive as relatively wealthier or more sustainable living areas. Children and other family members often join the family in the urban area, straining already stretched urban resources. Consequently, as mobile, ever-growing populations in many areas of South Africa fail to eventually return to their homes, sustainable delivery of mental healthcare is a growing problem in many sectors of society, and especially so in underserviced and impoverished communities in many areas in South Africa (Bekker, 2002).

The South African historical context has arguably played a significant role in creating the current healthcare context underscored by poverty. Predemocratic institutionalised discrimination significantly influenced social life configurations, including access to health services and resources and the impoverishment of large sections of the South African population (Coovadia, Jewkes, Barron, Sanders, \& McIntyre, 2009). The common outcome is poor health relative to total health expenditure in the country, with a large gap existing between those who cannot afford medical insurance and those who can that is reflected in the burden of disease. The Commission on Social Determinants of Health (CSDH) found that health and illness follow a social gradient: health is worse the lower an individual is on the socioeconomic continuum (as cited in World Health Organisation, 2008). South Africa's social gradient is extremely steep as shown by the Gini coefficient that measures inequality (Leibbrandt, Woolard, McEwen, \& Koep, 2010). The World Health Organization reported in 2002 that those living in abject poverty were extremely vulnerable to infectious diseases such as tuberculosis and HIV/AIDS, exacerbated by food insecurity and income poverty (as cited in Lutge \& Friedman, 2010). Worsened by the worldwide recession, the devastating and ongoing drought, and increased prices, these healthaffecting factors have impacted on infant mortality, nutrition, and the access to, and supply of, essential healthcare services (Statistics South Africa, 2016; United States Agency for International Development, 2016). Despite these conditions and the evident need for basic healthcare service, the long-awaited South African national public healthcare service delivery system is yet to become a reality (Marais, 2010).

Postapartheid South Africa made forward strides in certain areas of national legislation and improvement in health systems management (Harrison, 2009; Whittaker, Shaw, Spieker, \& Linegar, 2011). The 2002 Mental Health Care Act, the objective of which was to provide the best possible healthcare, brought fundamental changes in mental health: the provision of community-based care, treatment, and rehabilitation; the appropriate level of care; and referral to suitable establishments, 
and care and rehabilitation rights, for people with severe or profound intellectual disabilities (Sukeri, Betancourt, \& Emsley, 2014).

The deinstitutionalisation of mental healthcare that followed the 2002 Act saw it relegated to the primary healthcare (PHC) sector (Burns, 2008). With the severe understaffing of this division, the PHC sector struggled to meet the demands of the Act and although this Act heralded some positive changes, the Eastern Cape Province faced great challenges. For instance, the deinstitutionalisation of psychiatric patients led to a dramatic reduction of acute and subacute inpatient beds, and a pressured increase on available beds usually reserved for the seriously ill patients. This resulted in the "revolving door" patient or high frequency user-well for short time spans, then requiring hospitalisation, only to be discharged prematurely to accommodate a more severely ill patient. Although the initial deinstitutionalisation was meant to improve the quality of care of mental health users, unfortunately, the accompanying community-based services that were supposed to oversee the discharged mental health users were not in place and thus patients became the responsibility of the community or household (Botha et al., 2010). Alongside the shortage of psychiatrists was the lack of child and adolescent psychiatric services in the province (Sukeri et al., 2014), with most people in the local community unable to obtain help, thereby remaining invisibly voiceless at the margins of society, unable to advocate for better service (Saraceno et al., 2007).

Given this context, mental health problems go largely unreported, are often accompanied by other physical diseases, and are compounded by substance abuse (Department of Health, 2014). Many people choose to seek advice from traditional healers (Sutherland, 2016; Truter, 2007) and there is often societal stigma attached to accessing formal mental health services (Burns, 2008). With the integration of mental health services into primary health care, the burden has shifted to households in the community, which feel the pressure and cannot always cope with individuals who have chronic mental illnesses (Breen et al., 2007).

At the Nelson Mandela University (NMU), ${ }^{2}$ where the Missionvale Psychology Centre (MPC) is housed, community responsive engagement is recognised as one of the key general functions of higher education and a specific key function of the university. This action enriches scholarship, research and creative activity, enhances the university's curriculum-based teaching and learning, prepares educated and engaged future citizens, and strengthens democratic values and civic responsibility. In addition, it contributes to the public good and social transformation agendas, and boosts social, economic, and ecological sustainability (NMMU, n.d.). As an engaged institution, NMU is committed to contributing to the development and upliftment of immediate and surrounding communities-geopolitical groups of people with both visible and invisible links who reside in specific localities, share governance structures and systems, and often have a common cultural and historic affiliation as organising principle (Guttmacher, Kelly, \& Ruiz-Janecko, 2010).

Given that universities are hubs of training and knowledge with extensive access to networks of current and future professionals in the field of mental health, they afford both students and community members ideal platforms from which to promote and receive beneficial healthcare. However, it is often challenging to ensure ethical engagement with communities whilst providing high quality training to emerging professionals. A common problem in many health sciences disciplines is the provision of sufficient training platforms for multifarious clinical skills development opportunities while striving to meet the needs of community expectations (Pillay, 2003).

\footnotetext{
${ }^{2}$ Formerly, Nelson Mandela Metropolitan University (NMMU).
} 
In order to facilitate engagement that brings about social change, the predominant call today is for the redesign of professional health education. Unable to keep pace with the challenges of fast demographic and epidemiological changes as new and varying risks threaten health security, the challenge to move away from traditional teaching and training methods in order to address common goals calls for transformative teaching and training (Frenk et al., 2010). These challenges have provided the local university with the impetus and opportunity to adapt curricula and practice in order to be more relevant and responsive to societal requirements and needs. Thus, the NMU's Faculty of Health Sciences has embarked on a goal-driven process to transform its health education model by focusing its teaching and learning within a community context rather than within the traditionally exclusive lecture- and laboratory-based ivory tower paradigm. Through the MPC mental health initiative, the university has afforded its psychology students unique opportunities to hone their clinical skills at a community-based training site while simultaneously discovering significance in what they do as opportunities for rich learning and service delivery provide purpose and meaning for both students and clients (Frankl, 2000).

This article reports on how one South African university, located in a densely populated, underserviced, and impoverished urban area of the Eastern Cape Province, has risen to and negotiated the challenges of providing appropriate and sustainable mental health care through an on-campus psychology clinic, the Missionvale Psychology Centre. As a biopsychosocial training site for future clinical and counselling psychologists, the MPC affords these students a platform to hone their psychological service skills by treating a full range of emotional and psychological challenges, thus underscoring good health and wellbeing among people.

\section{Theoretical Framework}

Guiding the study is the theory of transformative learning because desired competencies centre on changes in self-understanding, revising one's belief system, and making changes in lifestyle, resulting in deep structural shifts in thoughts, feelings, and actions that give meaning to the experience (Mezirow, 1997). Through involvement and collaboration with the local community, students can cocreate potential social change (Mertens, 2009), and this article reports on the transformative learning journey at the NMU. In addition to highlighting the challenges and successes experienced along the way, this article also reflects on lessons learned working in the MPC.

\section{Methodology}

This study applies reflective practice principles in that it retrospectively reviews the authors' responses to experiences, events, and information-looks for meaning in the responses to these experiences while seeking solutions to problems. It requires reflection-in-action whereby thinking and action simultaneously interact, engendering learning and problem reframing as well as reflection-on-action, which calls for retrospective analysis that creates experiential knowledge (Schön, 1983).

Epistemologically, an interpretative framework guides the narrative inquiry in obtaining a better understanding of the study through individuals' personal experiences and truthful reporting of complex social realities (Tuli, 2010). Gibbs' reflective cycle (1988) and Kolb's experiential learning cycle (1984) served as guides because the idea that knowledge could be created on the basis of concrete experience, and new concepts could be tested in novel situations, resonated well with the authors (Carr, 2006; Leitch \& Day, 2000).

A number of sources contributed to our data base. From our own lived experiences, both having managed the MPC since 2013 while working in the community, we noted stories from the people about 
the people; we were kept up to date by the medical personnel at the nearby clinic and had informal conversations with past students and staff members. Existing records and reports were available for perusal, and the greatest learning came from our reflection on current practices at the end of each year, together with adjustments made to learning and teaching. As experienced educators and clinical healthcare practitioners working in the community, and as authors committed to transforming mental health education, we were well situated to evaluate the complex, dynamic, and unique successes and challenges around sustained university-community engagement in the field of mental health teaching and learning.

In ensuring trustworthiness, credibility is underscored by cross-questioning the authors' variety of experiences in the establishment of the MPC, prolonged engagement with the community, and the subsequent building of trust and persistent observation of the subject matter over a long time period. Transferability is heightened in that sufficient descriptive information is provided to ensure replication of some of these concepts in similar projects.

From an ethical standpoint, the MPC, as part of a training institution accredited for internship purposes, has a duty to its students to provide a well-balanced, appropriate professional training programme with a broad spectrum of work and relevant working and training facilities. Praxis is guided by fundamental values of the Health Professions Council of South Africa (HPCSA, 2005, 2008) and, because work was done out in the community by staff and students, Pienaar's (2014) community engagement ethics guideline developed by the University of South Africa served as a sound navigational tool. This document includes knowledge production, social value, scientific value, validity and ethical merit, fair subject selection, the nature of participation, informed consent, and community involvement in the research (Pienaar, 2014).

\section{A Specific Case Study: Missionvale Psychology Centre (MPC)}

The Missionvale Psychology Centre was largely both physically and academically nonaligned to the NMU's Department of Psychology, and closure remained imminent until 2012 when the department elected to operationalise the university's new vision and mission and redress existing clinical practice. This involved staffing and a paradigm shift in community engagement and service delivery thinking. Numerous challenges appeared along the way and constant dynamic adaptations had to be made.

\section{Challenges on the journey.}

Servicing the MPC.

At the time of the MPC's reestablishment in early 2013, there was one permanent staff member-a receptionist-to oversee the administration of the MPC. A few clients were seen by two registered counsellors placed at the MPC for a 6-month period with weekly supervision by a permanent member of staff. They supported clients with counselling and basic psychometric needs, assisted by three volunteers from the university's psychological society who attempted to reduce the long waiting list by phoning clients to determine whether or not intervention was still required.

Community members and schools required continuous service delivery throughout the year, and NMU students' semester rotations caused an ebb-and-flow service delivery system, creating confusion and misunderstanding for many stakeholders. Inconsistent service delivery made establishing trust with the community problematic. Due to staff shortages, the community's needs could not be met, a 3-year waiting list developed, and walk-in clients could not be accommodated. Highlighting these challenges resulted in a campaign for more staff members. A clinician-manager was appointed in 2014, and student training and community service commenced. Furthermore, three full-time registered 
counsellors began 6-month internships, thereby accommodating walk-in clients. The registered counsellors began to work through the long waiting list while building trust relationships with local schools by conducting assessments and providing psychoeducational workshops. The MPC began to run efficiently and effectively, as was seen by the rise in clients from 142 in 2014, to approximately 550 in 2016. Following discussions with various practicum coordinators, staff members began to rethink internship planning in order to offer a more efficient service.

Through working with local primary schools, it was soon realised that the mental health needs of adolescents were inadequately addressed. Requests for help came from many high schools, specifically for drug user support. Other areas of grave concern were sexual abuse, teenage pregnancy, HIV/AIDS, and family violence. Discussions began early in 2015 and two different departments from two universities, the NMU psychology department and the Walter Sisulu University (WSU) psychiatry department, together with the local Level 2 regional hospital of the Eastern Cape Department of Health (Dora Nginza), agreed to work together in a groundbreaking interinstitutional collaboration project in order to better serve the adolescent community in the Port Elizabeth area. This project, known as the Ukhanyo Psychiatric Clinic (denoting hope, light, and enlightenment), became part of the MPC due to the suitable site, strong infrastructure, and access to broad neuropsychological assessments that were limited at the local hospital. A consultation room was made available and equipped for use by two psychiatry registrars, each working a one day a week, 6-month rotation. The services of a clinical social worker from the local hospital's psychiatry department were subsequently made available.

In 2015, two occupational therapists completing their community service training at the local hospital joined the team, followed by two psychometry interns in 2016. A full-time registered psychologist strengthened the team together with an advanced psychiatry nurse completing his postgraduate practical programme. Both spoke isiXhosa and initiated a much needed support group for local isiXhosa Red Cross caregivers. The unique skills cluster was further enhanced by the addition of two social work interns on 6-month rotations, affording the community improved access to social work interventions with the students gaining broad learning experience.

A dispensing pharmacist and a medical specialist with many years of palliative care as well as experience with children living with severe cognitive challenges both began work in mid-2017, and improved community service delivery and greater inter-professional student education are anticipated. With the establishment of the medical school in 2020, the following additions could include a medical practitioner, a speech therapist and audiologist, either a physiotherapist or biokineticist to begin community rehabilitation on campus, a dietician, a remedial teacher to address barriers to learning, as well as a volunteer legal services practitioner.

\section{Internal networking to obtain staff "buy-in."}

At the time of its reestablishment in 2012, the MPC, disregarded as an academic hub, marginalised, and perceived to be isolated, possessed no true identity and operated in an institutional vacuum. It appeared that academic staff members did not fully understand the MPC's role and focus as a community teaching centre. Given that staff had to select and supervise students who would serve clinical internships at the centre, their buy-in was necessary because exposure and engagement with the community could add value and richness to student learning opportunities.

Buy-in from faculty management was spearheaded by the Dean of Health Sciences who identified the MPC as a blueprint for further viable clinical training sites, and slowly a clearer understanding developed when staff members were encouraged to visit the MPC, noting where their students would 
fit in to the clinical training picture. Coordinators could then proceed with suitable placements, satisfied that their students would obtain rich experiential training.

That the MPC was recognised for its potential as a springboard for community-responsive service delivery with future duplication, provided the credibility that was needed by the MPC. A token service fee encouraged a sense of client ownership and helped to change the institutional mindset of the MPC as a drain on faculty funding to that of future self-sustainability.

Initially there was sufficient relevant working space but as the MPC's service delivery expanded, networking with university support staff became vital. In 2015, with working space at a premium that could deter supplementary professional service offers, additional space had to be negotiated. At the beginning of 2016, the original Vista University Clinic was returned to the Department of Psychology and refurbished as a psychometric hub.

A valuable networking opportunity for the authors was an invitation to join the Health Sciences Faculty's Transformation in Health Science Education project committee. From 2018, all health sciences students will begin with common biopsychosocial modules to instil a strong ethos of interdisciplinary teamwork right from the start of their training. From 2nd year onwards, the bulk of teaching will be carried out on a broad clinical training platform-out of the classroom into the real world-through the use of blended learning modalities whilst learning and serving in the local community. Being involved in teaching and learning transformation was a valuable opportunity that enabled the MPC to become part of the larger faculty project, establishing itself as a viable, responsive, sustainable clinical training site: an exemplar that faculty could replicate in the future.

\section{External networking with stakeholders in the local community.}

Meeting the community on home ground provided MPC staff with opportunities to better understand challenges facing the community, and strong alliances were forged. However, finding time to be in the community was difficult because academic and clinical schedules were heavy. The authors had to make engagement with the community a priority, becoming boundary spanners between the community and academia, working with civic and nongovernment organisations, government departments, and donors.

The Missionvale Care Centre (MCC) was one of the first stakeholders to align itself with the MPC. Established in 1988, it has run for 27 years as a faith-based nonprofit organisation. It operates entirely on donor funding, providing for the community's spiritual and basic physiological needs such as limited nutrition, clinical and pharmaceutical care, and clothing. Furthermore, a primary school established on its grounds caters for educational needs. Strong relationships have been established between the MCC and the MPC as, together, they offer an holistic community service. The MPC addresses the mental health aspect of community wellness while the MCC caters for other needs. The placement of two social work interns at the MCC in 2016 offered a much needed service and further strengthened community ties and trust.

The lack of community exposure was initially a challenge. Inviting representatives from local businesses to visit the MPC and experience community engagement for themselves afforded opportunities to better understand the need for such a facility, and offers of help followed the visits. Through the exchanging of goods for services, such as assessments and workshops in return for offers to refurbish the MPC, donations were received in the form of flooring, paint, and new and secondhand furniture. 
Distance that needed to be travelled.

Students, academic staff, and clinicians were initially reluctant or unable to travel 22 kilometres from the main campus in order to see clients or to supervise students. The struggle to balance travel time and academic programmes, meeting schedules, timetables, and clinical practice sessions proved problematic. Student transportation was negotiated and eventually shuttle buses were made available whereby students could move between campuses safely at no additional cost. Furthermore, having set internships replaced the need for students to travel to different sites because they now worked on one clinical site in a 6-month rotation.

In future, travel between campuses will be ameliorated. With the first intake of medical students in 2020, a living and learning environment will be established on the Missionvale Campus where the clinical coordination of the Health Sciences Faculty will be based. This will bring the health sciences students close to the clinical training platforms in the community with a future student residence envisaged either on this campus or at the adjacent Dora Nginza Hospital.

\section{Language proficiency.}

The lingua francas of Missionvale are predominantly Afrikaans and isiXhosa. However, other African languages are spoken in the area due to the migration of people from other areas as well as foreign nationals living in the area. The dearth of isiXhosa-speaking interns and registered counsellors resulted in one student who could speak isiXhosa having to carry the largest Xhosa caseload, and a waiting list developed. Although MPC management has attempted to address this challenge, obtaining sufficient isiXhosa-speaking student interns has not always been possible. However, this dilemma has been recognised at management level and the new health sciences curricula will include compulsory isiXhosa and Afrikaans modules for all students studying in the Health Sciences Faculty.

\section{Highlights from the development.}

Having addressed the challenges that were faced during the development of the MPC, the authors need to highlight the positive outcomes.

Collaborating with existing community agencies such as the Missionvale Care Centre has been a privilege for the authors. The managers of the Missionvale Care Centre see the MPC as part of the Missionvale family and Bethelsdorp community, referring their patients with mental health issues to the MPC, and visiting themselves for debriefing and support. Of significance is the formal community engagement agreement recently signed between the university top management and the Missionvale Care Centre, which gained community approval because it demonstrates that the University is listening and willing to help-bringing "gown to the town."

The second highlight has been a cognitive shift for many of the students as they have come to realise that multidisciplinary teamwork is both possible and rewarding, resulting in altered perceptions. No one practitioner is complete without the other; no one clinician can operate alone; no mental health discipline can stand alone, and the sum is so much greater than its parts.

Thirdly, from a staffing perspective, the MPC has more than trebled in 4 years as a result of the placement of additional and divergent groups of interns because clinical coordinators can see value in a community training site. With the inclusion of the Ukhanyo Psychiatric Clinic as part of the MPC, a broad specialist clinical spectrum is available in disciplines other than psychology, and academic and teaching staff from other departments are realising the relevance of the MPC and are becoming more involved. 
Fourthly, the client base has increased because many more clients can be accommodated than before, which also means that a wider range of challenges are being addressed as more specialist clinicians are available for immediate consultation and fewer clients need further referral to other agencies. Clients call it their "one-stop shop" because they are referred in-house, and only need to walk down a passage to another room to obtain supplementary or further service. The second suite of rooms has provided adequate space for current specialised interventions. Although the MPC does not directly address poverty in the community, by offering a variety of services, it is able to address the different mental health needs that are exacerbated by poverty.

\section{Lessons learnt.}

Significant lessons were learnt as part of the process of establishing and growing the MPC as a multidisciplinary university-community collaboration project based on a university campus situated in a South African township.

\section{An understanding of, and sensitivity to, the relationship between mental health and poverty.}

The need to understand the relationship between mental health and poverty is of the utmost importance. Lund et al., (2010, 2011) and Patel and Kleinman (2003) all underscored the connection between common mental disorders such as depression, anxiety, and somatoform disorders and poverty, as well as the link between the burden of disease and disability in low- and middle-income countries. Universities play an important role in generating knowledge about these connections, and in creating spaces for collaboration where these problems can be addressed in incisive and critical ways.

In Missionvale, the cycle of mental health and poverty pervades the community. Along with psychological problems, residents worry about unemployment, housing, disability, and social grants (Mkize \& Kometsi, 2008). As a result of unidentified and untreated mental illness, remaining in poverty is a risk that exists for many community members-yet, living in poverty brings its own set of risks of possible mental ill-health. By providing multifaceted interventions by trained professionals, the university can aid communities in managing the multifarious psychological, social, and biological determinants of mental ill-health, which may well contribute to improving community mental health and reducing health service costs and the burden on the state.

\section{Being responsive to the needs of a community in a collaborative and bidirectional manner.}

At the MPC, unrealistic community expectations often led to service delivery confusion. Palpable disappointment that not all social problems could be solved at the MPC was a lesson learnt in clear communication when developing mutual conversation with community stakeholders. Establishing collaborative community needs demands clarity regarding specific services and support (Pienaar, 2014). Furthermore, making mutual choices rather than imposing decisions on the community in a unilateral way is essential (Janse van Rensburg, 2014). Clear and frequent face-to-face communication in a formalised structure ensures that all stakeholders are included in the process, regardless of perceived power differences and that a collaborative vision of possibilities can arise.

Having students work alongside and in collaboration with the Missionvale community has helped to enable reciprocal knowledge sharing and generation, where the university and community stakeholders engage as equal partners and are able to utilise local knowledge, engendering potential learning experiences for both. In addition, students have discovered valuable assets in the community who have contributed to their learning. The community in which the students work is innovative and resourceful, affording opportunities in which they can act, reflect, dialogue, and research (de Beer, 2014). 
Involving community members at all levels.

A university often enters into associations with its community with theoretical background knowledge, underscoring unequal power relationships-yet both partners are mutually dependent and interrelated (Babbie \& Mouton, 2011; Pienaar, 2014). An important lesson learnt was that the community quickly felt powerless if the university was perceived as imposing possible solutions to community problems and, thus, delicate boundary spanning was necessary. Boundary spanning is viewed as facilitating teaching and learning between the university and the community, and it demands delicate balancing of power between the two in order to meet mutual objectives (Kaars \& Kaars, 2014). The boundary-spanning work done by the MPC management team in the building of community bridges was central to intergroup relations and essential to effective and efficient operations (Friedman \& Podolny, 1992; Weerts \& Sandmann, 2010).

Having interns speak to the residents, listen to their narratives, and assess the possibilities for psychoeducation and self-development opportunities, allowed them to experience the community at grassroots level, learn how to network effectively, and discover incongruities between the community requests and what the university thought that the community needed and expected.

\section{The adaptation of university curricula to serve a community-based African training context.}

Equity in health service delivery through partnering with the community can drive transformation in health science education through curricula alteration and decentralisation of the training platform. The MPC is ideally positioned to optimise transformative thinking and learning where a new and different type of graduate is envisaged: one who is exposed to inter-and trans-professional education and practice (IPEP) with the emphasis on community-based teaching and learning.

To reengineer primary health care (PHC), all health sciences students, regardless of discipline, need to be trained in basic PHC and community psychology, and involvement in community engagement should be built into each year of study, utilising the appropriate skillset at various training levels. For students, the sharing of knowledge on various levels while working together has self-growth potential whereby positive, professional self-concepts and high self-ideals develop. Transformative learning changes perspectives in self-understanding, belief systems, and behaviour through what is learnt in the classroom and opportunities to apply the new knowledge in other settings by discovering, exploring, and integrating the new learning. When working in the community, knowledge creation is reciprocal, and this mutual engagement can lead to the discovery of community-based career paths (Slavich \& Zimbardo, 2012).

Dirkx (1998) explained that the student, as an active participant in the learning process, cocreates and constructs what is learnt while learning, helping to make her or him a problem solver. By bringing various niche core skills together with complementary skills, client/patient-centred and populationbased health work is enhanced. Working as a team, students learn the competencies of effective teamwork, critical analysis, ethical conduct, scientific enquiry, coping with uncertainty, planning and managing for the future, and effective health-systems leadership (Frenk et al., 2010). A number of specialised disciplines, while adapting to societal needs and common goals can, together, create a common language-one removed from hyperspecialisation-a language rooted in competent complimentary disciplines that is able to construct transdisciplinary conceptual frameworks for addressing diverse health problems (Mendez, 2015). Innovative, progressive work in this direction is already taking place at other South African universities and NMU's MPC hopes to make a significant contribution to the defining of this transformational process. 


\section{Facilitating attitudinal change.}

As mentioned before, some academic staff, concerned that the specialised disciplinary nature of the MPC as a psychology hub would begin to alter as a result of multidisciplinary service provision, thought the project was unfeasible-which resulted in slow institutional and departmental buy-in. However, delicate diplomacy and exposure to the project gradually aided attitudinal change. Furthermore, the effect of working at the MPC has led students to discover community-based career paths. Fully aware of the underreporting of mental health in the community and the complexity of existing taboos, experience has shown us that clients have begun to find a home for their problems and appear to be comfortable consulting with the clinicians and interns.

\section{The cost effectiveness of establishing and maintaining the clinical training site.}

Historically, the MPC has been viewed as a mission-like nonprofit-making entity rather than a resourcegenerating unit. De Beer (2014) explained that financial self-sustainability is imperative and warned against perpetuating the legacy of dependency. In continuing to provide handouts or free services, a university may well be sustaining dependence, scarcity, disparity, and inequality. A decision was made to charge a nominal fee for services rendered by the MPC, using a sliding tariff scale for clients who could not afford to pay the fee in full, and free service for destitute clients.

The MPC's income has risen as services have expanded and a greater variety of professional skills has become available. A key aspect to sustainability is to share staff positions and resources with others. In future, the MPC could recruit people or positions in other organisations, which can be shared at low or no cost (e.g., clerical staff, volunteers, government community service programmes) and should continue to solicit in-kind support and barter for items and services that would otherwise need to be purchased (e.g., donations of office supplies from a local business).

\section{Addressing local school-related issues.}

Children living in poverty fear domestic violence, have attachment issues, poor nutrition, or drug and alcohol abuse amongst a host of other co-morbidities, and are severely challenged academically, emotionally, and socially (Walsh \& Galassi, 2002). This accurately describes the cohort that forms the majority of referrals to the MPC from the more than 370 schools and a number of informal crèches and day care centres in the Nelson Mandela Bay Metropole.

With the absence of school psychologists and concomitant support structures for learners experiencing problems, the MPC had to rapidly adjust clinical focus. Initially offering schools a purely psychological (counselling) service, the MPC staff expanded service delivery to include scholastic interventions such as group and individual assessments for alternative school placement, school readiness, cognitive ability, specific learning disabilities, trauma debriefing, and self-care sessions. Expectations grew rapidly in the community and staff had to resort to alternative plans to address the demand. School requests were triaged, with the MPC management staff often stepping into the breach to stem the tide. Workshop programmes were developed and facilitated, and support groups were offered to the public, schools, community organisations, and parents by students in the various disciplines working as teams.

Through these interactions, the students highlighted a lack of after-school care in the area and the formation of homework clubs involving education students is envisaged in the current academic year. Given that foundation phase education students are based on the Missionvale campus, this initiative offers a rich transdisciplinary opportunity for tutoring and remedial support for local learners. Children will be able to study in a safe space on campus under the supervision of qualified educators and educators-in-training. In addition, sourcing retired teachers who are valuable community assets could 
add rich knowledge and experience. Accreditation as a teaching site has recently been awarded to the MPC by the South African Department of Education, and short mental health enrichment courses have been planned and will soon be on offer to further educate school teachers and interested individuals. The MPC is, therefore, an example of an ideal community site that offers biopsychosocial support to individuals, groups, and schools

Reflecting on our experiences as researchers, we soon realised that because knowledge is relational, connecting with the community that had its own vested interests and a possible reluctance to address potential change could make interaction difficult. The lack of understanding of psychological services was palpable in the community, which limited our initial interaction with community members and stakeholders. This resulted in an initial reluctance to access the services until the local NGOs slowly began to advocate the services as valuable and essential.

Moving to a campus situated in a township necessitated a constant reexamination of our own personal deep-seated values, prejudices, and biases. Daily interaction assisted us in understanding what we had to do and why we had to do it. However, convincing our academic peers and students was a battle because few understood our fervour and mission. Combining our broad skills bases with those of the students-in-training had potential to effect change in the community and we thus committed ourselves totally to the project.

By default, our teaching practice changed from the traditional practice to transformative pedagogy as we immersed our students in authentic learning experiences that held a myriad of perspectives, challenged their beliefs, values and knowledge, and helped them to reflect critically, thus gaining a sense of critical consciousness and agency (Mezirow, 1997). What surprised and delighted us the most were the shifts in students' previously held beliefs, and their urgency to support social change. For some, career goals began adjusting as they saw their role as mental health practitioners in the field rather than in city consulting rooms. To date, three graduates who completed their internships at the MPC have volunteered their services.

Transformative learning is gaining ground as collaborative interaction with fellow clinicians-in-training and the community appears to have deepened our students' understanding of pressing social issues, and aiding their development as change agents. Moving from a solo approach to multidisciplinary teamwork, they came with fresh approaches to challenges and with palpable youthful energy as, together, they honed their clinical skills. Feedback underscored their understanding of the course content relevance and, in many instances, curriculum redundancy and knowledge gaps.

\section{Conclusion: Recommendations and Implications}

Two recommendations for necessary exploration are the voices and reflections of the students who have had field experience as well as the voices of the community members, both of which contributed to the experiential learning process of knowledge transfer and enablement. Further studies could serve as a springboard for action research because the authors recognise the people on the ground as invaluable sources of local knowledge, wisdom, and insight that can contribute to new knowledge creation. Credit must go to the community members who have helped to guide service provision. Continued work in and with the community will provide researchers and students with further opportunities to discover the rich assets that are embedded within the community.

Organisations rather than local people have begun to recognise the advantages of a multidisciplinary service and the necessity of substantial education around mental health in the community. Informal feedback sessions with local school staff members have identified the MPC as a safe space for learners 
and staff members alike. The students who worked in a variety of community settings discovered valuable assets in the community who exposed the students to new learnings. They found that, together, they were able to address issues that affected the mental health of the community, thereby discovering extremely strong and resilient people in the community. Despite distressing personal circumstances, the community has taught the MPC rich life lessons that are changing insular academic and professional attitudes.

There are certain practices that could be incorporated to improve the MPC provision in the future. Staff capacity expansion, the necessity of having far more isiXhosa-speaking interns, sustainable income generation, and impactful change of academic curricula are essential. Knowledge gaps that appeared as the students interacted with the community have resulted in them voicing the urgent need for a different type of psychology, one that addresses community mental health issues from an Afrocentric perspective.

Given that engaging with communities is not an add-on activity for universities but the core of service learning where the curriculum responds to regional and national needs (Bender, 2007), experiential training that develops a student's sense of social responsibility, commitment to professional and personal development, and an understanding of lifelong academic enrichment should become core modules in the new curriculum. Students are enabled to become advocates for social change when faced with the harsh realities of community life (Diab \& Flack, 2013; Mendez, 2015). Having lived this experience, the authors firmly underscore their argument for, and belief in, the need for multidisciplinary mental healthcare that is necessary in an ever-changing world-whereby students hone their clinical skills in an altered way, one in which they work alongside other health sciences practitioners and community assets as part of multidisciplinary teams.

In reviewing the challenges that have arisen through attempting to simultaneously meet community and student needs, a number of lessons have been learnt that could be of benefit to practitioners in comparable positions. The insight gained from the MPC experience may benefit mental health practitioners, and the principles for good practice identified here could be applied in other centres or sites faced with similar challenges as part of the social responsibility and student training agendas of universities in developing countries.

\section{References}

Babbie, E., \& Mouton, J. (2011). The practice of social research. Cape Town, South Africa: Oxford University Press.

Bekker, S. (2002). Diminishing returns: Circular migration linking Cape Town to the Eastern Cape. South African Journal of Demography, 8(1), 2001-2002.

Bender, C. (2007). Pathways of change for integrating community service-learning into the core curriculum. Education as Change, 11(3), 127-142.

Botha, U., Koen, L., Joska, J., Parker, J. Horn, N., Hering, L., \& Oosthuizen, P. (2010). The revolving door phenomenon in psychiatry: Comparing low-frequency and high-frequency users of psychiatric inpatient services in a developing country. Social Psychiatry and Epidemiology, 45(4), 461-468.

Breen, A., Swartz, L., Flisher, A., Joska, J., Corrigall, J., Plaatjies, L., \& Mc Donald, D. (2007). Experiences of mental disorder in the context of basic service reforms: The impact on caregiving environments in South Africa. International Journal of Environmental Health Research, 17(5), 327-334. 
Burns, J. K. (2008). Implementation of the Mental Health Care Act (2002) at district hospitals in South Africa: Translating principles into practice. South African Medical Journal, 98(1). Retrieved from http://www.scielo.org.za/scielo.php?script=sci arttext\&pid=S0256-95742008000100023

Carr, W. (2006). Philosophy, methodology and action research. Journal of Philosophy of Education, 40(4), 421-435.

Coovadia, H., Jewkes, R., Barron, P., Sanders, D., \& McIntyre, D. (2009). The health and health system of South Africa: Historical roots of current public health challenge. The Lancet, 374, 817-834.

De Beer, S. (2014). Re-imagining the third sector and its engagement with higher education institutions and local neighbourhoods: From scarcity to sustainability. In M. Erasmus \& R. M. Albertyn (Eds.), Knowledge as enablement: Knowledge between higher education and the third sector in South Africa (pp. 119-144). Bloemfontein, South Africa: SUN Media.

Department of Health (DoH). (2014). Department of Health Strategic Plan 2014-2019. Pretoria, South Africa: DoH.

Diab, P., \& Flack, P. (2013). Benefits of community-based education to the community in South African health science facilities. African Journal of Primary Health Care and Family Medicine, 5(1). Retrieved from http://www.phcfm.org/index.php/phcfm/article/view/474

Dirkx, J. (1998). Transformative learning theory in the practice of adult education: An overview. PAACE Journal of Lifelong Learning, 7, 1-14.

Frankl, V. (2000). Man's search for ultimate meaning. Cambridge, USA: Perseus.

Frenk, J., Chen, I., Bhutta, Z., Cohen, J., Crisp, N., Fineberg, H., . . . Serwadda, D. (2010). Health professionals for a new century: Transforming education to strengthen health systems in an interdependent world. The Lancet, 376(4), 1923-1958.

Friedman, R., \& Podolny, J. (1992). Differentiation of boundary spanning roles: Labor negotiations and implications for role conflict. Administrative Science Quarterly, 37(1), 28-47. http://doi:10.2307/2393532

Gibbs, G. (1988). Learning by doing. Oxford, UK: Oxford Polytechnic University.

Guttmacher, S., Kelly, P., \& Ruiz-Janecko. (2010). Community-based health education. San Francisco, USA: John Wiley.

Harrison, D. (2009). An overview of health and health care in South Africa 1994-2010: Priorities, progress and prospects for new gains. Retrieved from http://ftp.bhfglobal.com/files/bhf/overview1994-2010.pdf

Health Professions Council of South Africa. (2005). Criteria for the training and for the accreditations of institutions offering training of intern-psychologists. Retrieved from http://www.hpcsa.co.za/Uploads/editor/UserFiles/downloads/psych/psycho education/form 10 $\underline{3 . p d f}$

Health Professions Council of South Africa (2008). Guidelines for good practice in the health care professions: General ethical guidelines for the health care professions. Retrieved from http://www.hpcsa.co.za/downloads/conduct ethics/rules/generic ethical rules/booklet 9 infor med consent.pdf

Janse van Rensburg, E. (2014). Enablement: A foundation for community engagement through service learning in higher education. In M. Erasmus \& R. M. Albertyn (Eds.), Knowledge as enablement: Knowledge between higher education and the third sector in South Africa (pp. 41-61). Bloemfontein, South Africa: SUN Media. 
Kaars, P., \& Kaars, B. (2014). Views from inside a non-profit organisation: Facilitating reciprocal relations based on a shared value system. In M. Erasmus \& R. M. Albertyn (Eds.), Knowledge as enablement: Knowledge between higher education and the third sector in South Africa (pp. 162178). Bloemfontein, South Africa: SUN Media.

Kolb, D. (1984). Experiential learning: Experience as the source of learning and development. New Jersey, USA: Prentice-Hall.

Leibbrandt, M., Woolard, I., McEwen, H., \& Koep, C. (2010). Employment and inequity outcomes in South Africa. Cape Town, South Africa: Southern Africa Labour and Development Research Unit.

Leitch, R., \& Day, C. (2000). Action research and reflective practice: Towards a holistic view. Educational Action Research, 8(1), 179-193. http://doi:10.1080/09650790000200108

Lund, C., Breen, A., Flisher, A., Kakuma, R., Corrigall, J., Josaka, J., . . Patel. V. (2010). Poverty and common mental disorders in low and middle income countries: A systematic review. Journal of Social Science and Medicine, 71, 517-528.

Lund, C., de Silva, M., Plagerson, S., Cooper, S., Chisholm, D., Das, J., . . Patel, V. (2011). Poverty and mental disorders: Breaking the cycle in low-income and middle-income countries. The Lancet, 378, $1502-1514$.

Lutge, G., \& Friedman, I. (2010). The cycle of poverty, hunger and ill-health. In S. Fonn \& A. Padarath (Eds.), South African Health Review 2010 (pp. 101-106). Durban, South Africa: Health Systems Trust.

Marais, H. (2010). South Africa pushed to the limit: The political economy of change. Cape Town, South Africa: UCT Press.

Mendez, F. (2015). Transdiscipline and research in health: Science, society and decision-making. Colombia Medica, 46(3), 128-134.

Mertens, D. (2009). Transformative research and evaluation. New York, USA: Guilford Press.

Mezirow, J. (1997). Transformative learning: Theory to practice. New Directions for Adult and Continuing Education,74, 5-12. http://doi:10.1002/ace.7401

Mkize, N., \& Kometsi, M. J. (2008). Community access to mental health services: Lessons and recommendations. South African Health Research Journal, 11, 103-113.

Nelson Mandela Metropolitan University. (n.d.). Vision 2020 Strategic Plan. Retrieved from http://splan.nmmu.ac.za/vision-2020

Patel, V., \& Kleinman, A. (2003). Poverty and common mental disorders in developing countries. Bulletin of the World Health Organization, 81(8), 609-615.

Pienaar, S. (2014). Considering ethics: Enabling participatory knowledge sharing. In M. Erasmus \& R. M. Albertyn (Eds.), Knowledge as enablement: Knowledge between higher education and the third sector in South Africa (pp. 80-99). Bloemfontein, South Africa: SUN Media.

Pillay, J. (2003). Community psychology is all theory and no practice: Training educational psychologists in community practice within the South African context. South African Journal of Psychology, 33(4), 261-268.

Saraceno, B., van Ommeren, M., Batniji, R., Cohen, A., Gureje, O., Mahoney, J., ... Underhill, C. (2007). Global Mental Health 5: Barriers to improvement of mental health services in low-income and middle-income countries. The Lancet, 370, 1164-1174. http://doi:10.1016/S0140-6736(07)61263X 
Schön D. (1983). The reflective practitioner: How professionals think in action. London, UK: Temple Smith.

Slavich, G., \& Zimbardo, P. (2012). Transformational teaching: Theoretical underpinnings, basic principles, and core methods. Educational Psychology Review, 24(4), 539-606.

Statistics South Africa. (2016). Expenditure of GDP: Information note. Retrieved from http://www.statssa.gov.za/publications/P0441/Information note on Expenditure on GDP.pdf

Sukeri, K., Betancourt, O., \& Emsley, R. (2014). Lessons from the past: Historical perspectives of mental health in the Eastern Cape. South African Journal of Psychiatry, 20(2), 34-39.

Sutherland, T. (2016). A retrospective review of lifetime prevalence of traditional healer consultation by an outpatient sample of Xhosa schizophrenia sufferers (Unpublished master's thesis). University of Witwatersrand, South Africa.

Truter, I. (2007). African traditional healers: Cultural and religious beliefs intertwined in a holistic way. South African Pharmaceutical Journal, 74(8), 56-60.

Tuli, F. (2010). The basis of distinction between qualitative and quantitative research in social sciences: Reflection on ontological, epistemological and methodological perspectives. Ethiopian Journal of Education and Science, 6(1), 97-108.

United States Agency for International Development. (2016). The latest Southern African drought fact sheet. Retrieved from http://usaid.gov/sites/default/files/documents/1866/southern africa dr fs03 06-22-2016.pdf

Walsh, M., \& Galassi, J. (2002). An introduction: Counseling psychologists and schools. The Counseling Psychologist, 30(5), 675-681.

Weerts, D., \& Sandmann, L. (2010). Community engagement and boundary-spanning roles at research universities. The Journal of Higher Education, 81(6), 632-657.

Whittaker, S., Shaw, C., Spieker, N., \& Linegar, A. (2011). Quality standards for healthcare establishments in South Africa. South African Health Review 2011, 60-67.

World Health Organization. (2002). Report on infectious diseases: Scaling up the response to infectious diseases. Geneva, Switzerland: World Health Organization.

World Health Organization. (2008). Closing the gap in a generation: Health equity through action on the social determinants of health. Geneva, Switzerland: World Health Organization. 